\title{
Identification of Klebsiella species isolated from Modimola dam (Mafikeng) North West Province - South Africa
}

\author{
Gladys Penn Siri, Nomathamsanqa Patricia Sithebe* and Collins Njie Ateba
} Department of Biological Sciences, School of Environmental and Health Sciences, Faculty of Agriculture, Science and
Technology, North-West University, Mafikeng Campus, Private Bag X2046, South Africa.

Accepted 9 September, 2011

\begin{abstract}
Life on earth depends on water. However, there is scarcity of portable water supplies in South Africa especially in rural areas. This results to the consumption of untreated water that may be contaminated with microbial species such as Klebsiella. The aim of the study was to investigate Klebsiella contamination levels in water from the Modimola dam situated adjacent the Modimola village, in the North West Province, Mafikeng - South Africa. Nine water samples (three each) were collected from the upstream, middle-stream and down-stream of the dam. The samples were analyzed by plating on mFC and Eosin methylene blue agar plates. The blue isolates on $\mathrm{mFC}$ were counted and results recorded. The identities of metallic sheen colonies on EMBA were determined using Gram staining, preliminary (TSI and oxidase test) and confirmatory (API 20E, gapA specific PCR) tests. A total of 504 presumptive isolates were screened and $28(35.9 \%)$ Klebsiella species were positively identified. Despite the fact that faecal coliform bacteria were not detected in tap water, the level of faecal contamination was higher in samples obtained from the upstream than the middle stream and; than the downstream. All water samples collected from the different sites of the Setumo dam contained Klebsiella species and this indicates the risk that water from this dam can pose threat to the inhabitants of the Modimola community who use the water for fishing and some daily activities.
\end{abstract}

Key words: Klebsiella, Setumo dam, TSI, API 20E, gap A specific polymerase chain reaction (PCR).

\section{INTRODUCTION}

Bacteria that belong to the genus Klebsiella are facultative, anaerobic, non motile, Gram-negative rods that possess a prominent polysaccharide capsule (Umeh and Berkowitz, 2009). Klebsiella species exist as normal flora in the gastrointestinal tract of animals and humans (Podschun et al., 2001). Despite this, Klebsiella species can cause severe infections that include meningitis, bronchitis, bacteremia, pneumonia, urinary tract infections in humans and animals (Lai et al., 2000; Boye and Hansen, 2003; Jonas et al., 2004; Trautmann et al., 2004; Casolari et al., 2005; Maroncle et al., 2006; Lau et al., 2007). In humans these infections are common in patients who are admitted in hospitals and those who are immunocompromised.

${ }^{*}$ Corresponding author. E-mail: thami.sithebe@nwu.ac.za. Tel: +27-18-389-2416 or +27-82-905-7928. Fax: +27-18-389-2134.
Domestic animals such as cattle and horses are principal hosts for Klebsiella species (Podshchun et al., 2001). Improper farm management techniques and/or improper hygiene may facilitate contamination of water sources with Klebsiella species (Podschun et al., 2001). Thus most infections caused by Klebsiella species result from consumption of contaminated food such as rotten fish and/or water (Podschun et al., 2001; Kanki et al., 2002; Haryani et al., 2007). Klebsiella species have been found to cause infections in babies through the consumption of powdered infant formula that was contaminated with pathogenic strains (Liu et al., 2008). Improper deposition of human faeces can lead to contamination of the soil with Klebsiella species hence Klebsiella pneumonia has been isolated from vegetables such as dried bush okra (Corchorus olitorius) and African spider herb (Cleome gynandra) (Mpuchane and Gashe, 1996).

Virulence in Klebsiella species results from the presence of capsular polysaccharides (CPS), 
lipopolysaccharides, adhesions (Lai et al., 2000; Cartés et al., 2002). Moreover, the acquisition of iron exchange systems may result to severe clinical signs on infected individuals (Lai et al., 2000; Cartés et al., 2002). Klebsiella express two types of cell surface antigens viz; the $\mathrm{O}$ and $\mathrm{K}$ antigens that contribute to pathogenicity in these species (Umeh and Berkowitz, 2009).

Treatment of infections caused by Klebsiella species is usually achieved by administering antibiotics. However, treatment options become limited when infections are caused by Klebsiella species that are resistant to multiple antibiotics and this presents a severe challenge in immunocompromised individuals (Gupta et al., 2003; Seid and Asrat, 2005; Schelenz et al., 2007; Umeh and Bertowitz, 2009). Based on the aforementioned, there is a need to frequently assess the levels of contamination with Klebsiella species in water. This study was carried out to measure the level of contamination of Klebsiella species in water samples collected from Setumo dam adjacent Modimola Village. This dam is located near the sludge treatment plant and water from this plant is deposited into the dam. Animals in the nearby village drink water from the dam and also contribute in contaminating the water with pathogenic microorganisms. Individuals who live nearby this dam lack proper water facilities and they use water from the dam for household activities. Moreover, some individuals fish in the dam and these are consumed. This explains the need to determine the level of bacterial contamination in the water as this may have serious health implications on humans.

\section{MATERIALS AND METHODS}

\section{Sampling site}

Samples that were tested were collected from Modimola dam, in the Modimola Village. Modimola Village is about $30 \mathrm{~km}$ from the Northwest University, Mafikeng campus. It is situated adjacent to Unit 14, a residential area in Mmabatho, North West Province, South Africa. Modimola dam is located near the Mmabatho sewage treatment plant that effluent is discharged into. Due to the fact that the vegetation next to the dam is most often green, livestock graze near the dam and as such also drink water from this dam. The water is also used for other human activities such as swimming and laundry. This increases the level of pollution.

\section{Sample collection}

Nine (triplicates) water samples (three from each of the three different sites of the Modimola dam) were collected into sterile one liter Duran Schout bottles. These sites were assigned as; up-stream which is the inlet where water that has undergone secondary treatment and chlorination from the treatment plant is discharged. The next site was the middle-stream which is about $2 \mathrm{~km}$ from the inlet and finally the down-stream which is about $1.5 \mathrm{~km}$ from the middle-stream. Samples were collected while avoiding contamination and collection were done only in spring. The water samples were labeled properly, placed on ice to inhibit the growth of microorganisms and transported immediately to the Microbiology research laboratory for analysis. Tap water was used as a control during analysis.
Analysis of water samples using conventional microbiological techniques

\section{Determination of bacteria load in water samples}

Aliquots of $50 \mathrm{ml}$ of each water sample was filtered through a 0.45 $\mu \mathrm{m}$ Grid filter-unit (Type HA) using a Gelman Little Giant Pressure/vacuum pump machine (model 13156-Gelman Sciences, Michigan-USA). The filters were placed on m-FC agar plates using sterile forceps and plates were incubated aerobically at $44^{\circ} \mathrm{C}$ for 24 h. After incubation, blue colonies were observed on $\mathrm{m}-\mathrm{FC}$ agar indicating faecal coliforms. A colony counter was used to count these isolates and the results were recorded, as cfu/50 ml of water.

\section{Selective isolation of Klebsiella species}

Ten-fold serial dilutions were prepared from each water sample using $2 \%$ peptone water and aliquots of $100 \mu$ were spread plated unto (EMBA). The plates were incubated at $37^{\circ} \mathrm{C}$ for $24 \mathrm{~h}$. Presumptive colonies were sub-cultured on EMBA and the plates were incubated at $37^{\circ} \mathrm{C}$ for $24 \mathrm{~h}$. Pure isolates were Gram stained.

\section{Gram staining}

Presumptive isolates were Gram stained using standard methods (Cruikshank et al., 1975). Gram negative rods were retained for identification using biochemical preliminary tests.

\section{Preliminary biochemical tests}

Oxidase test: The reagents used in performing the Oxidase test were (Pro-Lab Diagnostics-United Kingdom) products. In carrying out this procedure, a sterile wire loop was used to transfer a colony unto a filter paper (Whatman International Ltd, Maidstone, England) and a drop of oxidase reagent was added to it. A sterile wire loop was used to mix the reagent and the bacteria cells. Results were read within $30 \mathrm{~s}$ and the formation of a purple colour was recorded as a positive test while no colour reported as oxidase negative. Klebsiella spp. are oxidase negative, thus all isolates that were oxidase negative were retained for confirmatory biochemical tests.

Triple sugar iron agar test(TSI): Triple sugar iron(TSI) agar obtained from Biolab, Merck, S.A. was used to determine the ability of presumptive Klebsiella isolates to utilize the three sugars; glucose, sucrose and lactose. In conducting this test, $63 \mathrm{~g}$ of TSI agar was dissolved into $1 \mathrm{~L}$ of sterile distilled water and $5 \mathrm{ml}$ was dispensed into McCartney bottles. The bottles were autoclaved. The media were allowed to solidify while the bottles were placed in slanting positions so as to create a slant and butt. The media was stab inoculated at the butt and streaked on the slant. Bottles were loosely closed and incubated at $37^{\circ} \mathrm{C}$ for $24 \mathrm{~h}$. The results were read and recorded based on colour change from red to yellow, gas production and $\mathrm{H}_{2} \mathrm{~S}$ production as determined by Forbes and Weissfeld (1998).

\section{Confirmatory biochemical test}

\section{Analytical profile index 20E (API 20E)}

API $20 \mathrm{E}$ is a standard test kit that is designed for the identification of bacteria that belong to the family Enterobacteriaceae. The test was carried out according to the instructions of the manufacturer (BioMériux, France). The results were read after incubation based on color changes with or without the addition of reagents. 
Table 1. Total number of bacterial count for water samples obtained at different points in the dam.

\begin{tabular}{cccc}
\hline \multicolumn{4}{c}{ Bacterial count (fecal coliforms)/ $\mathbf{5 0 ~} \mathbf{~ m l})$} \\
\hline Upstream (cfu/50 ml) & Middle stream (cfu/50 ml) & Downstream (cfu/50 ml) & Tap water (control) (cfu/50 ml) \\
\hline (US1) 720 & (MS1) 83 & (DS1) 51 & (TW1) 0 \\
(US2) 921 & (MS2) 103 & (DS2) 43 & (TW1) 0 \\
(US3) 1230 & (MS3) 68 & (DS3) 18 & (TW1) 0
\end{tabular}

US=Upstream, MS=Middle stream, DS=Downstream, TW=Tap water

Confirmatory identification of Klebsiella isolate(s) using polymerase chain reaction (PCR)

Nutrient broth was prepared and pure isolates from nutrient agar were inoculated into it. These were incubated overnight culture in a shaking incubator at $37^{\circ} \mathrm{C}$ at a rotation speed of $120 \mathrm{rpm}$ to enhance bacterial growth. PCR was then used to further confirm the identities of all the presumptive Klebsiella isolates

\section{Extraction of genomic DNA}

DNA genomes were extracted from the bacterial isolates using a DNA extraction kit (Catalog\# 732-6030-Biolab, South Africa) as directed by the manufacturer and the supernaths were stored in a freezer at $-20^{\circ} \mathrm{C}$ for PCR analysis. DNA was of good quality with no fragmentation.

\section{DNA amplification}

A total of 78 Klebsiella pneumoniae isolates were screened by specific PCR to confirm their identities through amplification of the gapA gene fragment. The primers are designed to amplify specific sequences on the chromosome that code for the gap $A$ gene that is responsible for synthesizing the protein glyceraldehyde 3phosphate dehydrogenase. PCR amplifications were performed using a mini cycler (CG1-96 Corbett Research, Australia). The reactions were prepared in $25 \mu$ l volumes which were made up of $10 \mu \mathrm{g} / \mu \mathrm{l}$ of the template DNA, $50 \mathrm{pmol}$ of each oligonucleotide primer

set (F:GTTTTCCCAGTCACGACGTTGTATGAAATATGACTCCACTCA CG;R:TTGTGAGCGGATAACAATTTCCTTCAGAAGCGGCTTTGA TGGCTT), 1X master mix, and RNase free distilled water. All PCR reagents were obtained from Fermentas, USA but supplied by the Ignaba Biotec Ltd, Sunnyside South Africa. The cycling conditions included an initial DNA denaturation step at $94^{\circ} \mathrm{C}$ for $3 \mathrm{~min} ; 34$ cycles of denaturation step at $94^{\circ} \mathrm{C}$ for $20 \mathrm{~s}$; primer annealing at $60^{\circ} \mathrm{C}$ for $30 \mathrm{~s}$ and primer elongation at $72^{\circ} \mathrm{C}$ for $30 \mathrm{~s}$. A final elongation was carried out at $72^{\circ} \mathrm{C}$ for $5 \mathrm{~min}$ and the PCR products were stored at $4{ }^{\circ} \mathrm{C}$. The proportion of Klebsiella species obtained at the different positions in the dam was determined and percentages were calculated by dividing the number of isolates confirmed by PCR in a particular site by the total number of isolates screened.

\section{Electrophoresis}

Electrophoresis was used to resolve the amplified DNA on a $1 \% \mathrm{w} / \mathrm{v})$ agarose gel. A horizontal Pharmacia biotech equipment system (model Hoefer HE9X; Amersham Pharmacia Biotech,
Sweden) was used to carry out Electrophoresis and this was run for $5 \mathrm{~h}$ at $60 \mathrm{~V}$ using $1 \mathrm{X}$ TAE buffer (40 Mm Tris, $1 \mathrm{Mm}$ EDTA and $20 \mathrm{mM}$ glacialacetic acid, $\mathrm{pH}$ 8.0). Each gel contained a $100 \mathrm{bp}$ DNA molecular weight marker (Fermentas, USA). The gels were stained in ethidium bromide $(0.001 \mu \mathrm{g} / \mathrm{ml})$ for $15 \mathrm{~min}$ and amplicons were visualized under U.V. light at $420 \mathrm{~nm}$ wave length (Sambrook et al., 1989). A Gene Genius Bio Imaging System (Syngene, Synopties; UK) was used to capture the image using Gene Snap (version 6.00.22) software. GeneTools (version 3.07.01) software (Syngene, Synoptics; UK) was used to analyze the images in order to determine the relative sizes of the amplicons.

\section{Control strains}

K. pneumoniae ATCC (15611) was used as a positive control while no template reaction was used as a negative control.

\section{RESULTS}

\section{Determination of bacterial load in water samples}

The faecal coliform counts are shown in Table 1. The result indicates that water samples obtained from the upstream had a high colony count than those from the middle stream and the downstream. However, no bacteria were isolated from tap water.

\section{Gram staining and biochemical tests}

Results in Table 2 indicate that all the isolates were Gram-negative rods that were oxidase positive except for two from the middle stream. The isolates also ferment sugars glucose, lactose and fructose in the TSI medium producing a pattern that is characteristic for Klebsiella species (Forbes and Weissfeld, 1998).

\section{API 20E analysis}

The number of $K$. pneumoniae isolated was higher in the up-stream (37) than the middle stream (25) and the downstream (16). The presence of Klebsiella species indicate faecal contamination and the potential of water 
Table 2. Proportion of presumptive Klebsiella species identified using the Gram Staining, Triple Sugar Iron (TSI) Test, Oxidase Test and the API 20ETest.

\begin{tabular}{|c|c|c|c|c|c|c|}
\hline \multicolumn{7}{|c|}{ Biochemical tests and Gram staining } \\
\hline & GS & & TSI & & Oxidase test & API 20E test \\
\hline Location & & Sugar fermentation (+ve) & Gas (+ve) & $\mathrm{H}_{2} \mathrm{~S}(-\mathrm{ve})$ & & \\
\hline Up-stream & 168 & 102 & 160 & 168 & 168 & 35 \\
\hline Middle stream & 168 & 73 & 153 & 166 & 168 & 25 \\
\hline Down stream & 168 & 52 & 80 & 168 & 168 & 16 \\
\hline Total & 504 & 227 & 393 & 502 & 504 & 78 \\
\hline $\begin{array}{l}\text { Control strain } \\
\text { (ATCC 15611) }\end{array}$ & -ve rod & $+\mathrm{ve}$ & $+\mathrm{ve}$ & $-v e$ & $+\mathrm{ve}$ & +ve \\
\hline
\end{tabular}

$+v e=$ Positive for the test; - ve = Negative for the test; GS= Gram staining.

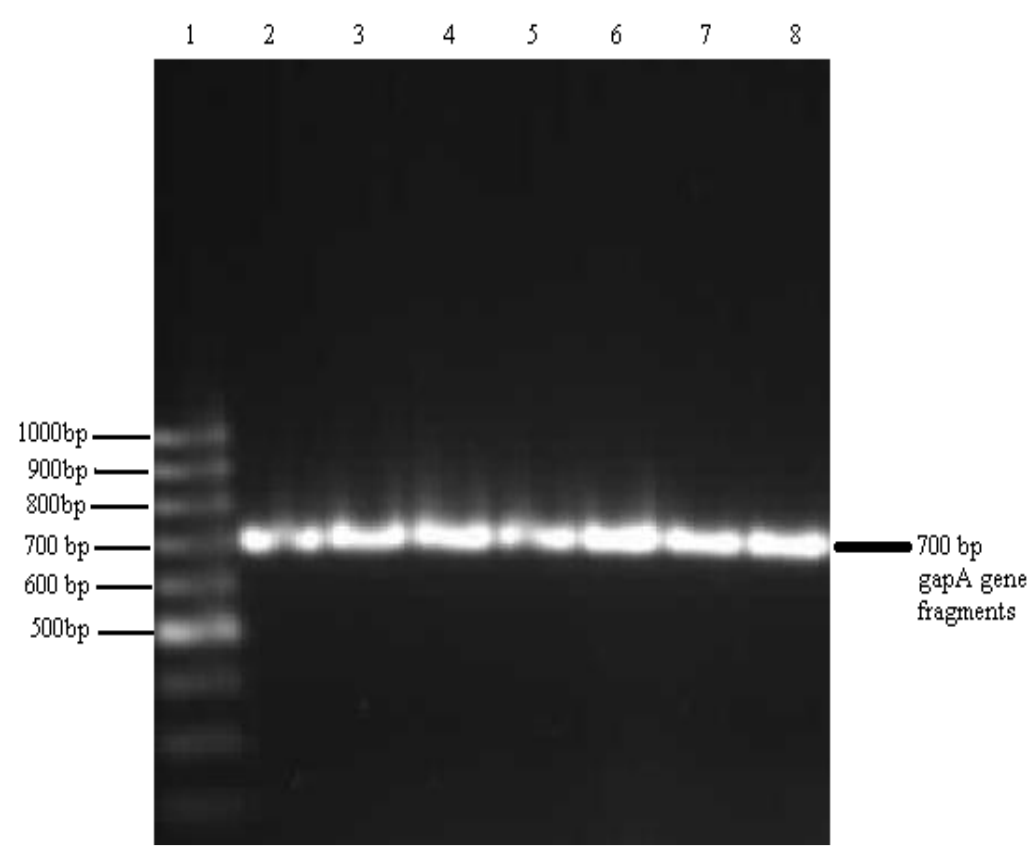

Figure 1. GapA gene fragments amplified from Klebsiella species obtained from the Modimola dam. Lane 1: 100 bp DNA maker, Lanes 2-7: gapA gene fragments from Klebsiella isolates obtained from the up-stream; middle stream and downstream; respectively: Lane 8: K. pneumoniae strain ATCC 15611 (Positive control).

from the dam to transmit these pathogens to humans who use the water.

\section{Confirmation of Klebsiella species using the PCR technique}

\section{Amplification of the gapA gene from suspected Klebsiella isolates using specific PCR analysis}

Specific PCR analysis of the gapA fragments did not produce the expected amplicon sizes (450 bp) in both the control and test strains. The fragments obtained were
700 bp as shown in Figure 1. Based on the PCR results a total of 28 isolates that belong to the genus Klebsiella were identified. The proportions of the isolates were higher in the up-stream $(15 ; 53.6 \%)$ than the middle stream $(8 ; 28.6 \%)$ and the downstream $(5 ; 17.8 \%)$.

\section{DISCUSSION}

It has been stipulated that the bacterial load in potable drinking water must be zero in $100 \mathrm{ml}$ of water sampled (WHO, 2003). The detection of bacteria of faecal origin in the present study indicated that the water was not safe 
and could serve as a potential source for the transmission of these pathogens to individuals who use the water. Fish obtained from the water could harbor parasites of some trematode species that are known to cause gastrointestinal diseases in humans when ingested (Arvanitidou et al., 2005). The infective stage of these parasites (metacercariae), are found in the edible tissues of freshwater fish or fish found in unhygienic water bodies (Abdussalam et al., 1995). These parasites are resistant to heating, freezing and salting (Abdussalam et al., 1995). Human infection with food borne trematodes may result from the ingestion of raw or inadequately processed food such as contaminated fish. Prevention of infections in humans in the Modimola Village may be achieved through environmental control of the water in the dam where fishes are caught and control of the first intermediate host (snails). Moreover, it is suggested that individuals of the Modimola Village be on the importance to properly cook fish from the dam before eating.

A further objective of the study was to confirm the identities of Klebsiella species using primary and PCR analysis. Several studies have been conducted to evaluate the efficiency of methods in identifying Klebsiella species (Lai et al., 2000; Haryani et al., 2007; Lau et al., 2007). PCR analysis has been reported to be more accurate in the identification of Klebsiella species when compared to other preliminary identification tests (Diancourt et al., 2005). A similar observation was obtained in the present study in which case some isolates that were preliminarily identified as Klebsiella species were not picked up in an optimized gapA specific PCR analysis. In the present study a 700 bp partial nucleotide sequence of Klebsiella genome was amplified as opposed to the expected $450 \mathrm{bp}$. A similar observation has been reported with the same primer sequence (Kong et al., 2002). The gapA gene sequences code for glyceraldehydes-3-phosphate dehydrogenase enzyme in Klebsiella species (Brisse et al., 2009). This enzyme plays an important role in glycolysis and gluconeogenesis by reversibly catalysing the oxidation and phosphorylation of G3P to the energy-rich intermediate $1,3 \mathrm{BPG}$. NAD ${ }^{+}$is a co-substrate for this reaction. GAPDH displays diverse non-glycolytic functions as well; hence its role depends on its location within the cell. Translocation of GAPDH to the nucleus acts as a signalling mechanism for programmed cell death, or apoptosis. The accumulation of GAPDH within the nucleus is involved in the induction of apoptosis. This explains the need to control the synthesis of this enzyme.

\section{Conclusion}

All water samples collected from the different sites of the Modimola dam contained Klebsiella isolates when analyzed. Klebsiella being a normal inhabitant of the intestinal tract of human and animals has acquired plasmids that carry virulence genes and increases their pathogenicity. Water from the dam showed high levels of faecal bacteria contaminants that indicate a potential threat to human life as stipulated by WHO. It is therefore suggested that humans in the Modimola Village should limit contact with water from the dam.

\section{ACKNOWLEDGEMENTS}

Authors are grateful to the North-West University, Mafikeng Campus for providing the funds and work space needed to conduct the research. The assistance received from the laboratory technician Mrs. Rika Hyser is highly acknowledged.

\section{REFERENCES}

Abdussalam M, Käferstein FK, Mott KE (1995). Food safety measures for the control of foodborne trematode infections. Food Cont., 6(2): 71-79.

Arvanitidou M, Kanellou K, Vagiona DG (2005). Diversity of Salmonella species and fungi in northern Greek rivers and their correlation to faecal pollution indicators. Environ. Res., 99: 278-284

Boye K, Hansen DS (2003). Sequencing of 16S rDNA of Klebsiella: taxonomic relations within the genus and to other Enterobacteriaceae. Inter. J. Microbiol., 292: 495-503.

Brisse S, Fevre C, Passet V, Issenhuth-Jeanjean S, Tournebize R, Diancourt L, Grimont P (2009). Virulent Clones of Klebsiella pneumoniae: Identification and evolutionary scenario based on genomic and phenotypic characterization. PLoS ONE. 4(3): e4982.

Cartés G, Borell N, Astorza B, Gómez C, Sauleda J, Alberti S (2002). Molecular Analysis of the contribution of the capsular Polysaccharides and Lipopolysaccharides $O$ side chain to the virulence of Klebsiella pneumonia in a murine model of bacterial pneumonia. Infect. Immun.,70(5): 2583-2590.

Casolari C, Pecorari M, Fabio G, Cattani S, Venturelli C, Piccinini L, Tamassia MG, Gennari W, Sabbatini AMT, Leporati G, Marchegiano P, Rupianesi W, Ferrari F (2005). A simultaneous outbreak of Serratia marcescens and Klebsiella pneumonia in a neonatal intensive care unit. J. Hosp. Infect., 61: 312-320.

Cruikshank R, Duguid JP, Marmoin BP, Swain RH (1975). Medical Microbiology, $12^{\text {th }}$ Ed, New York. Longman Group Limited, 2: 34.

Diancourt L, Passet V, Verhoef J, Grimnont PA, Brisse S (2005). Multilocus sequence typing of Klebsiella, pneumoniae nosocomial isolates. J. Clin. Microbiol., 43(8): 4178-4182.

Forbes AB, Weissfeld AS (1998). Bailey and Scott's Diagnostic Microbiology, $10^{\text {th }}$ edn. Mosby, St Louis, MO.

Gupta A, Ampofo K, Rubenstein D, Saiman L (2003). Extended Spectrum B- Lactamases-Producing Klebsiella pneumonia Infections: a review of literature. J. Perinatol., 23: 439-443.

Haryani Y, Noorzaleha AS, Fatimah AB, Noorjahan BA, Patrick GB, Shamsinar AT, Laila RAS, Son R (2007). Incidence of Klebsiella pneumonia in street food sold in Malaysia and their characterization by antibiotic resistance, plasmid profiling, and RAPD-PCR analysis. Food Cont., 18: 847-853.

Jonas D, Spitzmüller B, Daschner FD, Verhoef J, Brisse S (2004). Discrimination of Klebsiella oxytoca phylogenetic groups and other Klebsiella species by use of amplified fragment length polymorphism. Res. Microbiol., 155: 17-23.

Kanki M, Yoda T, Tsukamoto T, Shibata T (2002). Klebsiella pneumonia produces no Histamine: Raoultella planticola and Raoultella ornithinolytica strains are histamine producers. Appl. Environ. Microbiol., 68(7): 3462-3466.

Kong RYC, Lee SKY, Law TWF, Law SHW, Wu RSS (2002). Rapid detection of six types of bacteria pathogens in marine waters by multiplex PCR. Water Res., 36: 2802-2812.

Lai Y, Yang S, Peng H, Chang H (2000). Identification of Genes Present 
Specifically in a Virulent Strain of Klebsiella pneuoniae. Infect. Immun., 68(12): 7149-7151.

Lau HY, Clegg S, Moore TA (2007). Identification of $K$. pneumonia genes uniquely expressed in a strain virulent using a murine model of bacterial pneumonia. Microb. Pathog., 42: 148-155.

Liu Y, Liu C, Zheng W, Zhang X, Yu J, Gao O, Hou Y, Huang X (2008). PCR detection of Klebsiella pneumoniae in infant formula based on 16S-23S internal transcribed spacer. Inter. J. Food Microbiol., 125(3): 230-235.

Maroncle N, Rich C, Foresters C (2006). The role of Klebsiella pneumoniae urase in intestinal colonization and resistance to gastrointestinal stress. Res. Microbiol., 1587: 184-193.

Mpuchane SF, Gashe BA (1996). Presence of Escherichia coli, Klebsiella pneumoniae and Enterobacter species in dried bush okra (Corchorus olitorius) and African spider herb (Cleome gynandtra). Food Cont., 7(3): 169-172.

Podschun R, Ullmann U (1998). Klebsiella spp. as Nosocomial Pathogen: Epidemiology, Taxonomy, Typing Methods and Pathogenicity Factors. Clin. Microbiol. Rev., 11(4): 589-603.
Podschun R, Pietsch S, Höller C, Ullmann U (2001). Incidence of Klebsiella species in surface waters and their expression of virulence factors. J. Appl. Environ. Microbiol., 67(7): 3325-3327.

Sambrook J, Fritsch EF, Maniatis T (1989). Molecular Cloning: A Laboratory Manual, $2^{\text {nd }}$ edition. Cold Spring Harbor Laboratory Press Schelenz S, Bramham K, Goldsmith D (2007). Septic arthritis due to extended spectrum B-lactamase enzyme producing Klebsiella pneumonia. Joint Bone Spine, 44: 275-278.

Seid J, Asrat D (2005). Occurrence of extended spectrum B-lactamase enzyme from clinical isolates of Klebsiella species from Harar region, eastern Ethiopia. Acta., Trop., 95: 143-148.

Trautmann M, Held TK, Cross AS (2004). O antigen seroepidemiology of Klebsiella clinical isolates and implication for immunoprophylaxis of Klebsiella infections, Vaccine, 22: 818-821.

Umeh O, Berkowitz LB (2009). Klebsiella Infections. eMedicine.com.

Wealth Health Organisation (2003). Emmerging Issues in Water and Infectious Disease, World Health Organization, Geneva, Switzerland 